Grossowicz, N., Hayat, P. \& HalPern, Y. S. (1957). J. gen. Microbiol. 16, 576-583

\title{
Pyocyanine Biosynthesis by Pseudomonas aeruginosa
}

\author{
By N. GROSSOWICZ, PEYUTA HAYAT AND Y. S. HALPERN \\ Department of Bacteriology, The Hebrew University-Hadassah Medical School, \\ Jerusalem, Israel
}

SUMMARY: The formation of pyocyanine by resting Pseudomonas aeruginosa was studied. Glutamic acid was found to be a good substrate for this synthesis and could be replaced by several related amino acids $(\gamma$-aminobutyric acid, pyrrolidonecarboxylic acid, glutamine, aspartic acid, proline, hydroxyproline, arginine, histidine, alanine), and by some organic acids active in the tricarboxylic acid cycle (succinate, fumarate, pyruvate) when added together with ammonium ions. Magnesium ions were essential for pyocyanine synthesis and could not be replaced by other metals tested (Co, Fe). Pyocyanine formation was inhibited specifically by respiratory poisons $\left(\mathrm{KCN}, \mathrm{NaN}_{3}\right)$; $\mathrm{NaF}$, on the other hand, was not inhibitory.

Pyocyanine, the blue pigment produced by Pseudomonas aeruginosa, is known to possess antibiotic activity especially against the Gram-positive bacteria. Chemically, pyocyanine belongs to the phenazine group and is similar in structure to iodinine, a pigment produced by Chromobacterium iodinum (Clemo \& Daglish, 1950), and to chlororaphin, a green pigment formed by Pseudomonas chlororaphis (Kögl \& Postowsky, 1930). The synthesis of phenazine derivatives is, therefore, not uncommon among strictly aerobic micro-organisms.

Investigations published hitherto, including those reviewed in Topley and Wilson's Principles (1955), and those of Young (1947), Burton, Eagles \& Campbell (1947), Burton, Campbell \& Eagles (1948), and Hellinger (1951) deal with pyocyanine formation in growing cultures of $P$ seudomonas aeruginosa. The object of this investigation was to study pyocyanine formation in stationary cultures, and to chetermine the factors essential for its formation. A preliminary note was published previously (Halpern \& Grossowicz, 1954).

\section{METHODS}

The organisms used in this work were 2 strains of Pseudomonas aeruginosa from the stock culture collection of this Department. The bacteria were grown in Roux bottles containing 120-150 ml. Difco Nutrient Agar and incubated at $37^{\circ}$ for $24 \mathrm{hr}$. The organisms were taken up in saline, washed several times by centrifugation and resuspended in phosphate, borate, or 'Tris' (trihydroxymethylaminomethane) buffers. The concentration of organisms was determined by measuring the turbidity of a suitably diluted suspension in a Coleman Junior Spectrophotometer.

Pyocyanine assay. The experiments on the formation of pyocyanine were carried out in unstoppered $12 \times 75 \mathrm{~mm}$. or $24 \times 150 \mathrm{~mm}$. test tubes containing the bacterial suspensions and appropriate substrates in a volume of $1 \mathrm{ml}$.; the $\mathrm{pH}$ value was adjusted to $\mathbf{7 \cdot 8}$. The tubes were incubated statically at $37^{\circ}$. At 
the end of the experiment the tubes were shaken vigorously by hand for about 2 min. in order to convert all the pigment to the oxidized (blue) state. The pyocyanine was then extracted from the reaction mixture with $2 \mathrm{ml}$. of chloroform and measured in the spectrophotometer at a wavelength of $675 \mathrm{~m} \mu$. A solution of crystalline pyocyanine $2 \mathrm{HCl}$ (Nutritional Biochemicals Corp., Cleveland/Ohio, U.S.A.) made alkaline ( $\mathrm{pH} 7 \cdot 8)$ and similarly extracted with chloroform was used as a standard.

\section{RESULTS}

\section{Amino acid requirements}

Various amino acids were tested as possible substrates for pyocyanine synthesis. With glutamic acid as the sole carbon and nitrogen source, the yield of pigment was very good $(100-250 \mu \mathrm{g} . / \mathrm{ml}$.). However, even under optimal conditions not more than $2 \%$ of the glutamic acid was converted into pyocyanine, i.e. addition of $12 \mathrm{mg}$. glutamic acid to the system yielded $0.25 \mathrm{mg}$. of pyocyanine. This yield of pyocyanine was arbitrarily chosen as $100 \%$ to serve as a standard for the comparison of the amount of pyocyanine formed in the presence of other substrates. Pigment formation occurred also in the presence of alanine, arginine, aspartic acid, glutamine, histidine, hydroxyproline, proline, serine or threonine. No pyocyanine was formed in the presence of glycine, lysine, methionine, phenylalanine, tyrosine, tryptophane or valine. Asparagine, cysteine or leucine were adequate substrates for pyocyanine formation by only one of the two strains used (Table 1).

Since glutamic acid was found to be the best substrate for pyocyanine synthesis, compounds related to this amino acid were tested. Table 1 shows that pyocyanine formation in the presence of $\gamma$-aminobutyric acid was as great or slightly greater than in the presence of glutamic acid, while the yield of pigment in the presence of glutamine, proline, hydroxyproline or pyrrolidonecarboxylic (5-oxo-2-pyrrolidine carboxylic) acid was somewhat less. Of other amino acids known to be related metabolically to glutamic acid, ornithine proved better than arginine and citrulline. No pyocyanine was produced in the presence of lysine, but the decarboxylation product of lysine, cadaverine, produced $40 \%$ of the amount of pyocyanine which was formed in the presence of glutamic acid. The pyocyanine yield in the presence of aspartic acid was lower $(20 \%)$ than that found in the presence of its decarboxylation products $\alpha$ - and $\beta$-alanine, which both yielded about $75 \%$. Of the various aminobutyric acids only $\gamma$-aminobutyric acid was found to serve as an efficient substrate for pyocyanine synthesis (Table 1).

\section{Carbon sources for pyocyanine formation}

Succinate, fumarate, pyruvate and other organic acids were tested as sole sources of carbon in the presence of $\mathrm{NH}_{4} \mathrm{Cl}$ as nitrogen source. Pyocyanine was formed in the presence of some of these substances, while others were inactive (Table 1). No pyocyanine was formed when glucose was used as the only source of carbon. Addition of malate inhibited pyocyanine production in presence of glutamate, succinate $+\mathrm{NH}_{4}^{+}$or fumarate $+\mathrm{NH}_{4}^{+}$. 
Table 1. Effect of various substrates on the formation of pyocyanine

Total volume, $1 \mathrm{ml}$; ; organisms equiv. $6.7 \mathrm{mg}$. dry wt. $/ \mathrm{ml}$. Final concentration of substrates

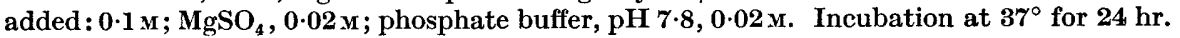

$\quad$ Substrate
L-Glutamic acid
$\gamma$-Aminobutyric acid
Pyrrolidonecarboxylic acid
L-Glutamine
DL-Proline
L-Hydroxyproline
DL-Ornithine
DL-Citrulline
L-Arginine
DL-Aspartic acid
L-Asparagine†
L-Alanine
$\beta$-Alanine
Glycine
DL-Serine
DL-Threonine
DL-Isoleucine
L-Leucine†
DL-Valine
DL-Methionine
L-Cysteine†
L-Cystine
DL-Lysine
DL-Histidine
L-Tryptophane
DL-Phenylalanine

Pyocyanine
formation
$\%^{*}$
100
110
75
70
80
90
55
20
40
20
100
85
70
0
55
35
0
30
5
0
20
0
0
40
0
0

\begin{tabular}{|c|c|}
\hline Substrate & $\% *$ \\
\hline DL-Tyrosine & 5 \\
\hline Anthranilic acid & 0 \\
\hline$\alpha$-Aminobutyric acid & 5 \\
\hline$\alpha$-Aminoisobutyric acid & $\mathbf{5}$ \\
\hline DL- $\beta$-Aminobutyric acid & 15 \\
\hline 2,4-Diaminobutyric acid & 0 \\
\hline Cadaverine & 40 \\
\hline Betaine & 10 \\
\hline Tyramine & 5 \\
\hline Tryptamine & $\mathbf{5}$ \\
\hline Ethylamine & 0 \\
\hline Triethylamine & 0 \\
\hline Tri-aminopropanol & 0 \\
\hline Ethanolamine & 0 \\
\hline$\alpha$-Ketoglutaric acid + & 55 \\
\hline Succinic acid $\ddagger$ & 30 \\
\hline Fumaric acid $\ddagger$ & 25 \\
\hline Pyruvic acid & 10 \\
\hline Acetic acid $\$$ & 35 \\
\hline Citric acid $\ddagger$ & 10 \\
\hline Malic acid $\ddagger$ & 0 \\
\hline Maleic acid $\ddagger$ & 10 \\
\hline Malonic acid $+*$ & 25 \\
\hline Oxalic acidt & 0 \\
\hline Glutaric acid $\ddagger$ & 0 \\
\hline Pimelic acid $\$$ & $\mathbf{5}$ \\
\hline
\end{tabular}

* Pyocyanine formation from glutamic acid was chosen arbitrarily as $100 \%$. The actua amount of pigment formed was about $0.25 \mathrm{mg}$.

$\dagger$ Active only with one strain.

$\ddagger \mathrm{NH}_{4} \mathrm{Cl}(0 \cdot 04 \mathrm{M})$ was added.

\section{Mineral salt requirements}

Examination of the role of metals in the pyocyanine synthesis was carried out with the aid of the chelating agent ethylenediamine tetra-acetic acid (EDTA). The addition of $0.3 \%$ EDTA prevented the formation of pyocyanine with glutamic acid as the substrate (Table 2). However, pyocyanine formation inhibited by $0.2 \%$ EDTA was completely restored by the addition of $\mathrm{Mg}^{++}$

Table 2. The effect of $\mathrm{MgSO}_{4}$ on formation of pyocyanine in the presence and absence of ethylenediamine tetra-acetate (EDTA)

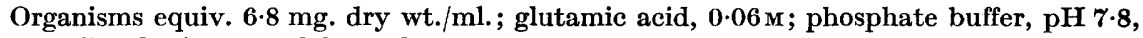
$0.02 \mathrm{M}$. Incubation at $37^{\circ}$ for $24 \mathrm{hr}$.

$\begin{array}{lcccc}\text { EDTA }(0.3 \% \mathrm{w} / \mathrm{v}) & - & - & + & + \\ \text {MgSO}_{4}(0.01 \mathrm{~m}) & - & + & - & + \\ \text { Pyocyanine formed } & \mathbf{1 4 4} & \mathbf{1 8 5} & \mathbf{8} & \mathbf{2 2 7}\end{array}$

$$
\text { ( } \mu \mathrm{g} . / \mathrm{ml} .)
$$


ions (0.002-0.01 M) (Fig. 1). On the other hand, $\mathrm{Co}\left(\mathrm{NO}_{3}\right)_{2}$ and $\mathrm{FeCl}_{2}$ (at concentrations of $0.0002 \mathrm{M}$ ) inhibited pyocyanine formation (Table 3). Phosphate was not necessary for pigment synthesis in the resting system. In growing cultures phosphate seems also to be dispensable (Jordan, 1899, as quoted from Topley \& Wilson, 1955); however, the newer work of Burton et al. (1948) claims the essentiality of phosphate for pyocyanine formation.

Table 3. The influence of various cations on pyocyanine production

Organisms equiv. 4.3 mg. dry wt./ml.; phosphate buffer, $\mathrm{pH} 7 \cdot 8,0 \cdot 02 \mathrm{M}$; total volume, $1 \mathrm{ml}$. Incubation at $37^{\circ}$ for $24 \mathrm{hr}$.

$\begin{array}{lcccccccccccc} & 1 & 2 & 3 & 4 & 5 & 6 & 7 & 8 & 9 & 10 & 11 & 12 \\ \mathrm{FeCl}_{3}(0.0002 \mathrm{M}) & - & + & - & - & - & + & + & + & - & - & - & - \\ \mathrm{Co}\left(\mathrm{NO}_{3}\right)_{2} .6 \mathrm{H}_{2} \mathrm{O}(0.0002 \mathrm{M}) & - & - & + & - & - & - & - & + & + & + & - & - \\ \mathrm{MnCl}_{2}(0.0002 \mathrm{M}) & - & - & - & + & - & - & + & - & - & + & + & - \\ \mathrm{MgSO}_{4}(0.05 \mathrm{M}) & - & - & - & - & + & + & - & - & + & - & + & - \\ \text { Glutamic acid }(0.02 \mathrm{M}) & + & + & + & + & + & + & + & + & + & + & + & - \\ \text { Pyocyanine formed } & 59 & 10 & 24 & 64 & 69 & 21 & 26 & 6 & 24 & 25 & 73 & 10\end{array}$
$(\mu \mathrm{g} \cdot / \mathrm{ml}$.

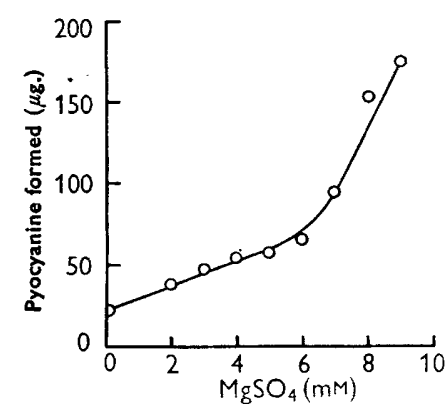

Fig. 1

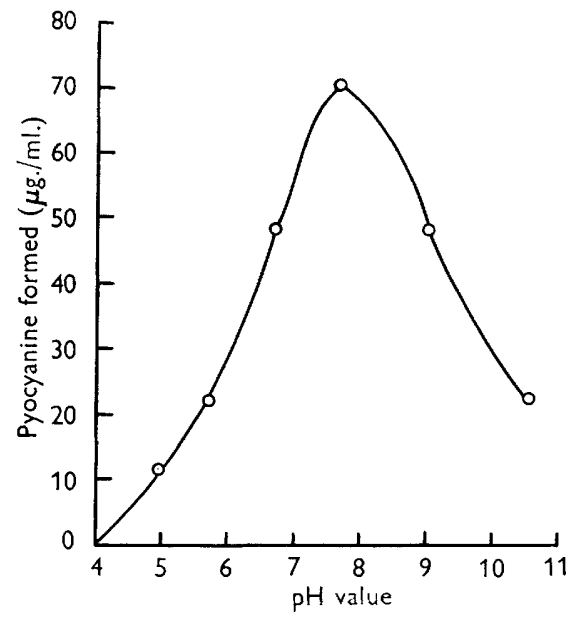

Fig. 2

Fig. 1. Dependence of pyocyanine synthesis on the concentration of $\mathrm{MgSO}_{4}$ in the presence of ethylenediamine tetra-acetate (EDTA). Total volume, $1 \mathrm{ml}$.; glutamic acid, $0.06 \mathrm{M}$; EDTA $0.2 \%(w / v)$; organisms equivalent to $6.5 \mathrm{mg}$. dry wt. bacteria; phosphate buffer, $\mathrm{pH} 7 \cdot 8,0 \cdot 02 \mathrm{M}$; incubation at $37^{\circ}$ for $24 \mathrm{hr}$.

Fig. 2. Effect of pH value on pyocyanine formation. Total volume, $3 \mathrm{ml}$; glutamic acid, $0.067 \mathrm{M} ; \mathrm{MgSO}_{4}, 0.01 \mathrm{M}$; organisms equivalent to $6.5 \mathrm{mg}$. dry wt. bacteria $/ \mathrm{ml}$; buffers : pH 7.2 and below, McIlvaine's buffer; above $\mathrm{pH} 7 \cdot 2$, 'Tris' buffer.

\section{Effect of $\mathrm{pH}$ value on pyocyanine formation}

Fig. 2 shows that the synthesis of pyocyanine took place over a wide range of $\mathrm{pH}$ values with optimum synthesis at $\mathrm{pH} 7 \cdot 0-8 \cdot 0$. At $\mathrm{pH}$ values of $6 \cdot 0$ and $10 \cdot 0$ pyocyanine formation was only about $30 \%$ of that found at $\mathrm{pH} \mathrm{7-8}$. 


\section{The rate of pigment formation}

The synthesis of pyocyanine was rather slow; the minimal time required for measurable amounts of pigment to be formed was c. 6-8 hr. (Fig. 3). Experiments were carried out with the aim of enhancing the rate of synthesis of pyocyanine. Since oxygen is essential for its formation, the effect of aeration on the incubation mixture was investigated. When wider test tubes $(24 \times 150 \mathrm{~mm}$.) were used instead of the smaller ones, the final yield of pyocyanine was doubled, but the rate of synthesis was unchanged. Similar results were obtained when the reaction vessels were shaken in a Ross-

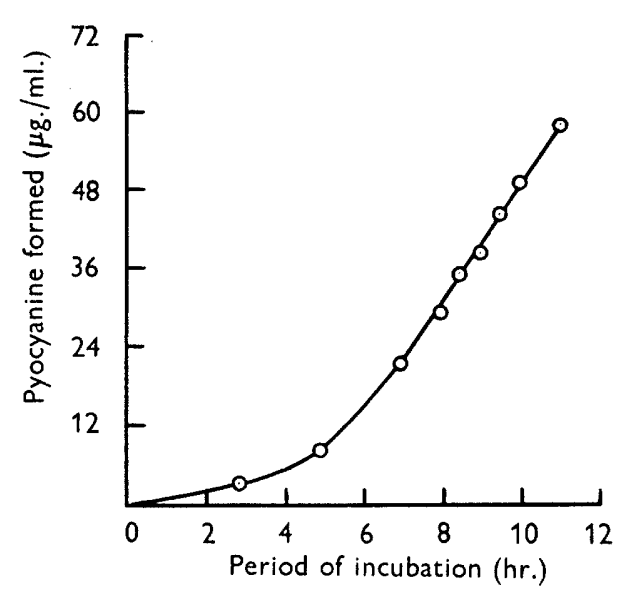

Fig. 3

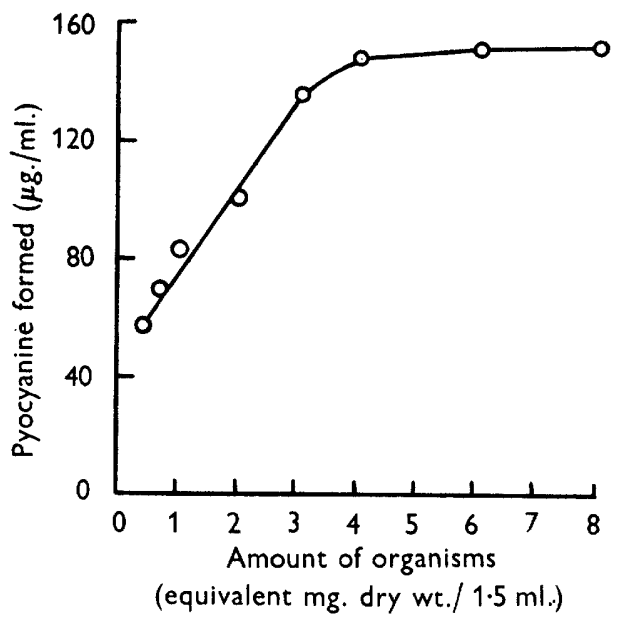

Fig. 4

Fig. 3. Pyocyanine synthesis as a function of time. Total volume: $10 \mathrm{ml}$; glutamic acid, $0.1 \mathrm{M} ; \mathrm{MgSO}_{4}, 0.02 \mathrm{M}$; organisms equivalent to $7 \mathrm{mg}$. dry wt. bacteria $/ \mathrm{ml}$.; phosphate

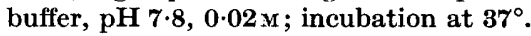

Fig. 4. Dependence of pyocyanine synthesis on the concentration of organisms. Total

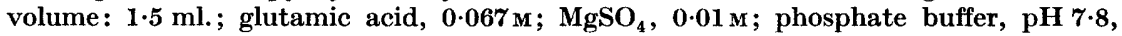
$0.02 \mathrm{M}$; incubation at $37^{\circ}$ for $24 \mathrm{hr}$.

Kershaw shaking apparatus. Stronger shaking in a reciprocating type of shaker inhibited pigment formation; in fact no pyocyanine at all was formed on vigorous shaking.

In view of the possibility that the slow synthesis was due to the lack, or insufficient formation, of some essential co-factor, the reaction mixture was enriched with yeast extract $(0 \cdot 2 \%, \mathrm{w} / \mathrm{v})$, tomato juice $(3 \%, \mathrm{v} / \mathrm{v})$, or a mixture of vitamins. The vitamin mixture contained the following substances $(\mu \mathrm{g} . / \mathrm{ml}$.$) :$ thiamine, 2.0; riboflavin, 1.0; nicotinamide, 15; Ca-pantothenate, 12.0; biotin, $0 \cdot 2$; pyridoxal- $\mathrm{HCl}, 2 \cdot 0$; pyridoxamine $2 \mathrm{HCl}, 2 \cdot 0$; choline, $3 \cdot 0$; inositol, 150.0; folic acid, $2 \cdot 5$; vitamin $\mathrm{B}_{12}, 0.01$; $p$-aminobenzoic acid, 0.1 . This was added in $0.1 \mathrm{ml}$. volumes to the $1 \mathrm{ml}$. incubation mixture.

In order to exclude the possibility that pyocyanine was synthesized by the bacteria multiplying during the incubation of the system, the following experi- 
ment was designed. A series of reaction mixtures, containing a constant amount of glutamic acid, $\mathrm{MgSO}_{4}$ and varying amounts of bacteria was set up. Fig. 4 shows that pyocyanine formation was proportional to the quantity of organisms added, indicating that the synthesis was not influenced by bacterial growth. In another experiment the concentration of organisms was kept constant while the concentration of glutamic acid varied from $0 \cdot 15$ to $2 \cdot 4 \%$ (w/v) (Fig. 5). The results obtained were essentially similar to those presented in Fig. 4. In other experiments colony counts and turbidity measurements were made; no evidence for bacterial growth during incubation for pyocyanine formation was found. On the contrary, a considerable decrease in colony count and some decrease in turbidity was noted.

\section{Action of various metabolic inhibitors}

It was hoped that by addition of metabolic inhibitors further information about the biosynthetic pathways in pyocyanine synthesis might be obtained. Several agents were also tested with a view to securing bacteriostatic conditions for the system studied without impairing pyocyanine formation. Penicillin, aureomycin or chloromycetin did not selectively inhibit bacterial growth or pyocyanine formation. At the lower concentrations of the antibiotics used both processes continued at normal rates, whereas higher concentrations, when inhibitory, affected both the growth of Pseudomonas aeruginosa and pyocyanine synthesis to the same extent. $\mathrm{KCN}$ or $\mathrm{NaN}_{3}$ at $0.001 \mathrm{M}$ inhibited pyocyanine synthesis by about $60 \%$, and at $0.01 \mathrm{M}$ the inhibition of synthesis was complete. Iodoacetate $(0.01 \mathrm{M})$ also prevented the formation of pyocyanine. At the given concentrations cyanide and azide inhibited growth as well, whereas iodoacetate did not. Thus iodoacetate inhibited selectively pyocyanine formation. $\mathrm{NaF}$ was not inhibitory of growth or synthesis even at $0.01 \mathrm{M}$ (Table 4). Thiomersalate at a concentration of 1: 30,000 completely prevented pyocyanine formation. Cysteine, glutathione and thioglycollic (mercaptoacetic) acid produced a marked decrease in the rate of pyocyanine synthesis.

\section{Table 4. Effect of $\mathrm{KCN}, \mathrm{NaN}_{3}$, and $\mathrm{NaF}$ on pyocyanine synthesis}

Glutamic acid, $0.081 \mathrm{M} ; \mathrm{MgSO}_{4}, 0.01 \mathrm{M}$; organisms equiv. $4.3 \mathrm{mg}$. dry wt. $/ \mathrm{ml}$.; phosphate buffer, $\mathrm{pH} 7 \cdot 8,0 \cdot 02 \mathrm{M}$; total volume, $1 \mathrm{ml}$. Incubation at $37^{\circ}$ for $24 \mathrm{hr}$.

$\begin{array}{lcc} & \begin{array}{c}\text { Inhibition of } \\ \text { Pyocyanine } \\ \text { formed } \\ (\mu \mathrm{g} . / \mathrm{ml} .)\end{array} & \begin{array}{c}\text { pyocyanine } \\ \text { formation } \\ (\%)\end{array} \\ \text { Control (no inhibitor added) } & 54 & 0 \\ \text { NaF }(0.01 \mathrm{M}) & 53 & 0 \\ \mathrm{KCN}(0.0001 \mathrm{M}) & 48 & 11 \\ \mathrm{KCN}(0.001 \mathrm{M}) & 24 & 56 \\ \mathrm{KCN}(0.01 \mathrm{M}) & 0 & 100 \\ \mathrm{NaN}(0.0001 \mathrm{~m}) & 45 & 17 \\ \mathrm{NaN}_{3}(0.001 \mathrm{M}) & 23 & 57 \\ \mathrm{NaN}_{3}(0.01 \mathrm{~m}) & 0 & 100 \\ \text { Mono-iodo-acetate }(0.01 \mathrm{M}) & 0 & 100\end{array}$




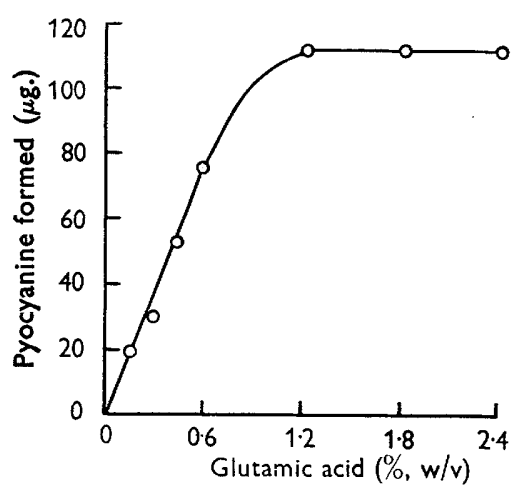

Fig. 5

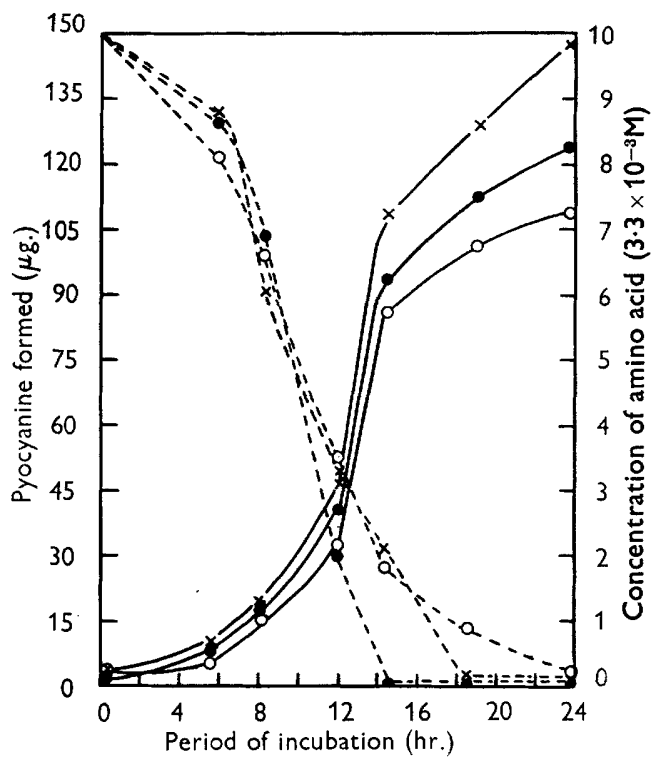

Fig. 6

Fig. 5. Influence of glutamic acid concentration on the formation of pyocyanine. Total volume: $1 \mathrm{ml}$; organisms equivalent $4.7 \mathrm{mg}$. dry wt. bacteria; phosphate buffer, pH $7 \cdot 8,0 \cdot 02 \mathrm{~m}$.

Fig. 6. The relationship between substrate disappearance and the formation of pyocyanine. Total volume: $1 \mathrm{ml}$; amino acids, $0.03 \mathrm{M} ; \mathrm{MgSO}_{4}, 0.02 \mathrm{M}$. Phosphate buffer, $\mathrm{pH} 7 \cdot 8,0.02 \mathrm{M}$. Incubation at $37^{\circ} . \times=\gamma$-aminobutyric acid; $\mathrm{O}=\mathrm{L}$-glutamic acid; = L-hydroxyproline. Solid line = pigment formation; broken line = disappearance of substrate.

\section{DISCUSSION}

Glutamic acid and some compounds closely related to it were thus found to be very good substrates for pyocyanine formation by non-proliferating suspensions of Pseudomonas aeruginosa. The greater production of pyocyanine in the presence of $\gamma$-aminobutyric acid than in the presence of glutamic acid raises the question as to whether the $\gamma$-aminobutyric acid serves as a suitable precursor in the biosynthesis or whether it enters the organisms more rapidly than glutamic acid and is there carboxylated to glutamic acid. The high yield of pyocyanine in the presence of $\beta$-alanine (the carboxylation of which to aspartate is not known to occur in this organism), suggests that the decarboxylated amino acids ( $\beta$-alanine, $\gamma$-aminobutyric acid) may function as such and not via glutamic or aspartic acids. On the other hand, the appreciable activity of $\alpha$-alanine might be explained by the ability of this compound to enter the Krebs cycle via pyruvic acid, and subsequently to undergo transformation to glutamic acid. The same mechanism might explain the effect of acetic, fumaric and succinic acids. This possibility appears plausible in view of the occurrence of the tricarboxylic acid cycle in various species of Pseudomonas (Barrett \& Kallio, 1953; Campbell, Smith \& Eagles, 1953; Claridge \& 
Werkman, 1954). The present work supports the view that glutamic acid holds a key position in pyocyanine synthesis and may be linked with the tricarboxylic acid cycle. Some insight into the sequence of the biosynthetic steps of pyocyanine formation may be gained by studying the relationship between the disappearance of the substrate and the formation of pyocyanine. Fig. 6 shows that the bulk of the substrates disappeared before measurable amounts of pyocyanine were formed and its synthesis continued after complete exhaustion of the added substrates. This relationship points towards the formation, from glutamic acid, of some unknown intermediary prior to its incorporation to form the molecule of pyocyanine.

The role of magnesium ions in pyocyanine formation was demonstrated in a magnesium-deficient system. The minimal effective amount of $\mathbf{M g}^{++}$ions was lower with glutamic acid than with any of the other substrates tested. The steep ascent of the curve resulting from the addition of $\mathbf{M g}^{++}$beyond 5-6 $\mu \mathrm{mole} / \mathrm{ml}$. (Fig. 1) suggests that this ion participates in more than one reaction step.

The rate of pyocyanine synthesis was rather slow. Attempts to enhance its rate of formation by increasing aeration, or by supplying missing nutrients, have so far failed. It might perhaps be assumed that some essential intermediary of unknown nature, which is synthesized at a very slow rate, acts as a limiting factor in the formation of pyocyanine. The specific sensitivity of the system to respiratory poisons suggests a function of respiratory enzymes in pyocyanine biosynthesis.

\section{REFERENCES}

Barrett, J. T. \& Kallio, R. E. (1953). Terminal respiration in Pseudomonas fuorescens: Component enzymes of the tricarboxylic acid cycle. J. Bact. 66, 517.

Burton, M. O., Eagles, B. A. \& Campbell, J. J. R. (1947). The amino acid requirements for pyocyanine production. Canad. J. Res. $25 \mathrm{C}, 121$.

Burton, M. O., Campbell, J. J. R. \& Eagles, B. A. (1948). The mineral requirements for pyocyanine production. Canad. J. Res. C, 26, 15.

Campbeli, J. J. R., Smith, R. A. \& Eagles, B. A. (1953). A deviation from the conventional tricarboxylic acid cycle in Pseudomonas aeruginosa. Biochim. biophys. Acta, 11, 594.

Claridge, C. A. \& Werkman, C. H. (1954). Intermediates of the aerobic dissimilation of 2-ketogluconate by Pseudomonas aeruginosa. Arch. Biochem. Biophys. $51,395$.

Cremo, G. R. \& Daglish, A. F. (1950). The phenazine series. VIII. The constitution of the pigment of Chromobacterium iodinum. J. chem. Soc. p. 1481.

Halpern, Y. S. \& Grossowicz, N. (1954). Pyocyanine synthesis by Pseudomonas aeruginosa. Bull. Res. Coun. Israel, 4, 210.

Hellinger, E. (1951). Requirements for pyocyanine production by Pseudomonas aeruginosa (Schroeter) Migula. J. gen. Microbiol. 5, 633.

KögL, F. \& Postowsky, J. J. (1930). UUber das grüne Stoffwechselprodukt des Bacillus chlororaphis. Liebigs Ann. 480, 280.

Topley and Wilson's Principles of Bacteriology and Immunity (1955). 4th ed., pp. 60, 598-600. Edited by Wilson, G. S. \& Miles, A. A. London: Edward Arnold and Co.

Young, C. (1947). Pigment production and antibiotic activity in cultures of Pseudomonas aeruginosa. J. Bact. 54, 109.

(Received 31 October 1956) 